\title{
TEATRO Y NUEVAS TECNOLOGÍAS: CONCEPTOS BÁSICOS
}

\author{
Anxo ABUÍn GONZÁLEZ \\ Universidade de Santiago de Compostela \\ feaabuin@usc.es
}

Resumen: Una vez establecidos los antecedentes para su estudio, el artículo pasa revista a los conceptos básicos que entran en juego al analizar la relación entre el teatro y las nuevas tecnologías y al comentar sus resultados más relevantes: virtualidad, interactividad, intermedialidad / remediación, realidad «aumentada» y lo post-humano. Se finaliza con una crítica de algunos modelos imperantes en la bibliografía más reciente.

Abstract: Once the forerunners to the study have been established, the article reviews the basic concepts that come into play in the relation between theatre and new technologies, commenting upon some of its most relevant products: virtuality, interactivity, intermediality / remediation, «augmented» reality, and post-human. The article finishes listing critical considerations of some of the most striking analytical models appearing in recent bibliographical sources. 
Palabras clave: Teatro virtual. Nuevas tecnologías. Interactividad. Remediación. Post-humano.

Key Words: Virtual Theatre. New Technologies. Interactivity. Remediation. Post-human.

Nadie puede dudar del creciente papel jugado por las nuevas tecnologías (entiendo por tales las digitales o numéricas) en el ámbito del teatro, de la danza o de la performance. En la más completa monografía dedicada a la «digital performance», Steve Dixon (2007) se refiere a fenómenos neoculturales muy diversos: el teatro que incorpora proyecciones manipuladas digitalmente, el que pone en escena robots, el que recurre a las prácticas de la Realidad Virtual, las performances que emplean tecnología telemática, los MUDs, los MOOs, los videojuegos, los CD-ROMs y las obras de net.art. Dixon conoce bien la importancia de las aportaciones de Robert Wilson, Robert Lepage, The Builders Association o Georges Coates Performance Works, que acostumbran a rodear a sus actores de imágenes tratadas electrónicamente. Merce Cunningham se acompaña de bailarines virtuales gracias a un software de animación (Life Form), descentrando los significados con un empleo muy intencionado de la técnica del collage, y estos avatares son frecuentes en los espectáculos de los grupos Troika Ranch (Mark Coniglio y Dawn Stoppiello) y Company in Space, por no hablar de las experiencias, más cercanas a nosotros, de La Fura dels Baus y Marcel.lí Antúnez, que comparte con Stelarc o con Matthew Barney una intensa experimentación con lo protético, lo posthumano o lo cyborg. La Realidad Virtual y la estética de los videojuegos ha sido utilizada por Blast Theory o David Saltz, y hoy ya nadie se extraña de conectarse a una performance on line (¿o sí?) o de manejar recursos de esta índole editados en CD-ROM.

En el fin de siglo hemos asistido a un regreso de lo grandiosamente espectacular, igual que pasó a comienzos del Xx con la aparición del cine. Sin duda uno de los factores determinantes en la expansión de esta nueva cultura visual es la eclosión de la tecnología digital, fuente incesante de imágenes asombrosas que producen excitación y estimulan a un público embriagado por innumerables visiones suntuosas. Las tecnologías numéricas han impulsado un profundo cambio en el sistema de las artes, cada vez más hibridizado, pues es casi imposible deslindar un medio de otro. Formamos parte de un nuevo paisaje cultural en el que las interferencias mediáticas son 
continuas. Ni siquiera la realidad escénica, avalada por siglos de experiencia comunicativa y semiótica muy definida, se ha salvado de este contagio, sin duda porque el teatro siempre ha gustado de desestabilizarse a sí mismo con la incorporación de lo nuevo. Es éste un lugar común que conviene analizar con calma en todas sus implicaciones actuales, pues nos hallamos ahora, sin duda, en una etapa de incunabilidad en la que todo se imita (o re-media) sin que sea posible separar el grano de la paja. Ante la necesidad de referencias a partir de las que orientarse, en un periodo en el que las nuevas tecnologías no han alcanzado todavía un lenguaje completamente propio ni un estatuto canónico que lo sustente, su estudio ha echado mano del teatro en busca de analogías, y de la teoría del teatro como lanzadera para una aproximación a fenómenos ciberculturales muy diversos. No todos ellos se corresponden, como veremos, con nuestra idea de teatro. La confluencia teatral se ve además acentuada por la dificultad de traer al español el término inglés performance ('ejecución'), cuya traducción se hace equivaler frecuente y a veces alegremente con una representación teatral o una práctica escénica tradicional.

Adelantemos, por último, en este preámbulo, que las nuevas tecnologías, aplicadas al teatro, todavía llaman demasiado la atención sobre sí mismas como medio o dispositivo, de manera que la transparencia comunicativa es en muchos casos un anhelo por el momento imposible. Quizás no sea siempre éste un inconveniente, pues podría valorarse como derivación de una sociedad cada vez más mediatizada por la pantalla de una televisión o de un ordenador, una sociedad que considera obsesivamente como nuevos tótems críticos las ideas de conexión, interactividad o multilinealidad.

\section{PRECURSORES}

Si trazásemos una genealogía de la performance digital, podríamos caer, como Dixon, en el exceso de dibujar una línea que uniera el deus ex machina griego con la Gesamtkunstwerk de Richard Wagner, con los experimentos en danza de Loïe Fuller, con las aportaciones de Oskar Schlemmer en los años 20 del siglo pasado, con el futurismo, el surrealismo y el dadaísmo: el collage, el fotomontaje, la instalación, los ambientes y los montajes ${ }^{1}$. Habría

\footnotetext{
1 Véanse las implicaciones de estos y otros antecedentes en el concepto de multimedia en los libros de Randall Packer y Ken Gordon (2001), Dan Harries (2002), Darren Toftson, Annemarie Johnson y Alessio Cavallaro (2002) y Nick Kaye (2007).
} 
que añadir a esta nómina, en lo que se refiere a las relaciones entre teatro y cine, los nombres de Erwin Piscator, Robert Edmond Jones y su «Teatro del Futuro», la Laterna Magika de Joseph Svoboda y Alfred Radok o el filmstage de Robert Blossom.

Pero, sin duda, su origen más directo se encuentra en el espíritu de la Black Mountain College, en el happening o en la performance, formas que en los 60 comenzaron a involucrar de manera abierta al público y a dirigir su papel cooperativo durante el proceso creativo. Entre el 13 y 23 de octubre de 1967 diez artistas experimentales, con la ayuda de treinta científicos y técnicos de los Laboratorios Bell, se reunieron durante diez meses, gracias a la invitación del ingeniero Billy Klüver, con el único fin de experimentar sobre las relaciones entre el teatro y las nuevas tecnologías. Cada uno de ellos tuvo oportunidad de presentar su trabajo al menos en dos ocasiones a un público, que, numerorísimo (Klüver habla de más de diez mil espectadores), contemplaba entre el asombro y el escándalo lo que allí se le mostraba. Guardamos constancia visual de estas 9 Evenings (Theater and Engineering), celebradas en edificio del 69th Regiment Armory, gracias a la filmación de Alfons Schilling. En ella vemos la propuesta de Steve Paxton (Physical Things), una estructura de polietileno inflada de aire por la que deambulaba el público al mismo tiempo que se proyectaban en las paredes imágenes de vídeo o que los altavoces emitían cantos de pájaros o un discurso sobre la pesca. Alex Hay (Grass Field) se cargaba de una peculiar mochila electrónica que transmitía al público los sonidos de su actividad muscular y cerebral, captados por sensores, y ordenaba cuidadosamente pedazos de tela en el suelo, antes de que una enorme pantalla mostrara al público su rostro extrañamente enorme. David Tudor (Bandoneon!) trataba el sonido de su instrumento distorsionándolo y haciéndolo interactuar con las luces del lugar y con tres monitores de televisión. Robert Rauschenberg (Open Score) ofrecía una peculiar partida de tenis: con cada golpe de pelota de los jugadores, convenientemente amplificado por unos altavoces, las luces se iban apagando; luego entraban quinientas personas en la oscuridad de la sala, grabadas por cámaras infrarrojas que transmitían esas imágenes para su proyección en tres grandes pantallas. Deborah Hay (Solo) situaba a sus bailarines ejecutando su danza encima de unas plataformas teleguiadas por diez personas sentadas en unas sillas. John Cage (Variations) ponía en funcionamiento treinta células fotosensibles que se activaban con el movimiento de los performers y que a su vez estaban conectadas a diferentes fuentes sonoras (una tostadora, un ventilador, varias radios...), mientras Cage permanecía hablando por un teléfono con diez líneas con diferentes lugares de Nueva York. Robert With- 
man (Two Holes of Water-3) llenaba el espacio con siete coches que transportaban televisiones y proyectaban vídeos o imágenes de televisión. Yvonne Rayner (Carriage Discreteness) utilizaba proyectores de vídeo mientras los performers manipulaban objetos en el escenario. Lucinda Childs (Vehicle) jugaba a coordinar un sónar con luces intermitentes y con doce altavoces. Y, por último, Oyvind Fahlström (Kisses Sweeter than Wine) desconcertaba a los espectadores con la yuxtaposición de actores-personajes muy heterogéneos (una chica del espacio, un idiota que presumía de saber multiplicar grandes cifras o una mujer en una piscina plástica llena de hielo), accesorios muy elaborados, televisiones y proyecciones de dispositivas de filmes ${ }^{2}$.

Se perdonará lo extenso de esta descripción, pero, más allá de la calidad indudable de las propuestas en este auténtico acontecimiento escénico, por no hablar de la impresionante nómina de colaboradores, están aquí reunidos los conceptos fundamentales que atraviesan la experimentación entre el teatro y las nuevas tecnologías durante las últimas décadas. Quizás dos sean los fundamentales: intermedialidad e interacción. Vayamos, pues, hacia ellos, añadiendo al hilo de la exposición algunos otros que ilustran la cuestión aquí tratada.

\section{INTERMEDIALIDAD, REMEDIACIÓN, POSMEDIALIDAD (Y UNA CODA SOBRE LA IDEA DE RIZOMA)}

Las relaciones interartísticas constituyen un componente básico del hecho teatral, incomprensible si no se parte de la coexistencia de los códigos sígnicos más diversos. Con los antecedentes sobresalientes de Goethe, Schiller o Novalis, Wagner defendió la necesidad de alcanzar una plenitud moral gracias a la institución de un arte verdaderamente completo, puesto que en el teatro se deben aunar todas las cualidades creativas. La obra de arte ideal nace de la ronda alternada de las artes (danza, música, poesía, arquitectura, escultura y pintura), conservando sus rasgos propios y por lo tanto eliminando sus límites en un resultado coherente, sincrético y autárquico. El Gesamtkunstwerk operaba como una aspiración utópica de una auténtica co-

\footnotetext{
${ }^{2}$ He podido consultar el filme de Schilling en el CD que acompaña el volumen Interagir avec les technologies numériques (VV. AA., 2004). En él se encuentran además materiales de gran interés: dos muestras de programación gráfica e interacción escenográfica (Isadora y Eyesweb), fragmentos de espectáculos de danza interactiva de Merce Cunningham, Troija Ranch (Future of Memory, 2002), Michel Bret, Franck Beaubois (Delay), Melanie Munt (Popsongs) o Cindy Van Acker (Corps 00:00). Para el trabajo de Cunningham con las computadoras, cf. Copeland (1999).
} 
municación colectiva, pero esta «obra de arte del porvenir», por utilizar el título de un libro fundamental del compositor alemán, ha cambiado definitivamente la historia de la escena europea, tal y como se puede ver en el trabajo de Élie Konigson (ed., 1995). Digamos ya que al logro de esa antigua aspiración se han incorporado con fuerza los nuevos medios tecnológicos.

Nadie duda hoy de la importancia de lo intermedial en el ámbito teatral. Es fácil asociar el concepto con lo posmoderno o lo posdramático por lo que tiene de supresión de fronteras genéricas, por su relación con lo híbrido y por lo que supone de búsqueda de nuevos modos de representación escénica, posibilitada en ocasiones gracias a la incorporación de los nuevos medios electrónicos. Podemos recordar, con Christopher Balme (1999) y Freda Chapple y Chiel Kattenbelt (2006), la diversidad de fenómenos que encubre la idea de intermedialidad, desde la transposición de un tema, la intertextualidad o la recreación de convenciones estéticas. Sitúese en este punto la relación entre el teatro y el cine, por ejemplo. Por otra parte, podría hablarse de una intermedialidad sintética que busca la fusión de lenguajes procedentes de diferentes medios; de una intermedialidad transmedial que nos pone ante funcionamientos de códigos y procedimientos que se encuentran en varios medios; o de una intermedialidad transformacional por la cual se produce el trasvase un medio a otro (con las consecuentes implicaciones ontológicas, de modo que podría hablarse también de una intermedialidad ontológica, cuando un medio se define en relación a otros). Todos estos casos son relevantes para el estudio de la relación entre el teatro y las nuevas tecnologías. En el primer caso podríamos situar la poética de Robert Wilson o Robert Lepage, a los que tampoco son ajenos los intereses transmediales. El modelo transformacional encajaría en lo que Steve Dixon ha denominado metal performances (Stelarc, Marcel.lí Antúnez, Guillermo Gómez-Peña, Istvan Kantor o Laura Kikauka) alrededor del tema de la humanización de los robots o la maquinización de los humanos, enfocado desde la perspectiva de lo monstruoso, transgresivo, violento o sexual, con una mirada que no escapa de la exhibición de lo artificial y exagerado.

En los últimos años se ha producido un intenso debate alrededor de la idea de autenticidad o liveness como rasgo constitutivo del teatro y lo performativo, que Gavin Carver y Colin Beardon (2004: 174) han concretado en las ideas de que el acontecimiento teatral está abierto al cambio (presenciado instantáneamente por un público) y de que los agentes humanos que participan en ese acontecimiento están realmente presentes durante la performance. Los estudios teatrales se han basado desde siempre en la creencia de que una representación sólo puede tener lugar en el aquí y el ahora del actor y del es- 
pectador, en el acto creativo in fieri que es el teatro. La representación teatral supone el encuentro con el Otro en un espacio y tiempo determinados, in vivo, una experiencia aurática de co-presencia, una propuesta de formación de subjetividades alternativas no exenta de cierto rango de resistencia ante los procesos homogeneizadores de la globalización, tal y como defendería Jorge Dubatti (2003). Desde el ámbito de la performance, Peggy Phelan (1993) ha proclamado la total independencia del teatro respecto de lo tecnológico, esto es, su carácter irreproducible: «Performance's only life is in the present. Performance can not be saved, recorded, documented, or otherwise participate in the representations of representations: once it does so, it becomes something other than performance» (1993: 41). Philip Auslander (1999), por su parte, considera superada la oposición liveness/mediatization, de manera que el teatro o la música actuales se sitúan en territorios en donde ambas posibilidades se mezclan ${ }^{3}$. Para Matthew Causey (2006: 30-38), es imposible pensar la realidad sin el condicionamiento mediador de lo televisual, tal y como han demostrado las prácticas artísticas de Nam June Paik, Bill Viola o Laurie Anderson. El teatro contemporáneo también ha buscado en la telepresencia televisual una forma de distanciamiento de las lógicas narrativas tradicionales y de alteración-fragmentación de la unidad del sujeto. De este modo, The Wooster Group, por ejemplo, confronta a sus actores con su propia imagen monitorizada (un primer plano que amplía una cara o centra un gesto), con la pregrabación de acciones protagonizadas por ellos mismos (la tensión entre dos tiempos y espacios distintos) o con fragmentos de vídeo o cine de procedencia muy diversa.

En realidad, la incorporación de los medios electrónicos a la esfera del arte tiene que relacionarse, como ha sabido ver José Luis Brea, con la aparición de las prácticas posmediales, derivadas de la evidente multiplicación de los canales y ámbitos mediáticos y «la convergencia de las tecnologías de postproducción computerizada y telecomunicación en la red Internet», de manera que se esboza «un mapa de posibilidades de distribución de las formas y prácticas artísticas que podemos calificar de postmedial» (2002: 30).

\footnotetext{
${ }^{3}$ «Mediatization is now explicitly and implicitly embedded within the live experience [...] within our mediatized culture, whatever distinction we may have supposed there to be between live and mediatized events is collapsed because live events are becoming more and more identical with mediatized ones [...]. Mediatization is the cultural context in which live performances are now inevitably situated [...]. Mediatization is not just a question of the employment of media technology; it is also a matter of what might be called media epistemology» (1999: 32-33). Es indudable la influencia de Jacques Derrida en el trabajo de Auslander, con antecedentes tan notables como el de Elinor Fuchs (1985). Cf. el reciente libro de Amy Petersen Jensen (2007), donde la idea de mediatización se aborda como la adopción de los contenidos y los contextos de los medios de masas para crear significados.
} 
Esto es, la irrupción de los medios numéricos nos sitúa ante un panorama abierto, desjerarquizado y descentralizado de las prácticas artísticas y teatrales, en el que la producción, distribución y recepción de las obras responderá a «la expansión creciente de un conjunto de nuevos dispositivos» tecnológicos. Los nuevos medios rompen de algún modo con la idea de unicidad o individualización de la obra de arte, impregnada desde la llegada de la televisión, como ha visto Samuel Weber (1996), de las ideas de telepresencia, transmisión, deslocalización o desplazamiento.

Para el estudio de la relación entre el arte y los medios electrónicos, es de especial interés el concepto de remediación, manejado por Jay David Bolter y Richard Grusin (1999) ${ }^{4}$. Bolter y Grusin definen el término como «the formal logic by which new media refashion prior media forms» (1999: 273). En la segunda edición de Writing Space, Bolter incide de nuevo en los procesos por los que «a newer medium takes the place of an older one, borrowing and reorganizing the characteristics of writing in the older medium and reforming its cultural space. [...] Remediation involves both homage and rivalry, for the new medium imitates some features of the older medium, but also makes an implicit or explicit claim to improve the older one» $(2001: 23)^{5}$. La remediación presentaría dos estilos visuales: la hipermediación (hypermediacy), que tiene como objetivo recordarle al usuario la utilización explícita del medio $^{6}$; y la inmediación (transparent inmediacy), que pretende de aquel que olvide la presencia del medio y acepte la convención según la cual está de verdad ante los objetos representados. Desde el punto de vista epistemológico, inmediación equivale a ausencia de mediación (o apariencia de ausencia): un medio es capaz de borrarse y desaparecer para el espectador, que puede contemplar los objetos directamente; hipermediación significaría por el contrario opacidad y consciencia del medio (el reconocimiento por parte do espectador de que el mundo se percibe a través de un filtro mediático). Desde una perspectiva psicológica, la inmediación y la hipermediación coin-

${ }^{4}$ La etimología de la palabra (del lat. remederi, 'curar', 'devolver la salud') inserta los procesos artísticos en la confianza de que cada medio remedia los anteriores, los mejora y supera: por ejemplo, la hipertextualidad narrativa sería superior a la novela por su añadido de interactividad.

${ }_{5}$ Puede compararse el término remediación con el de recapitulación, empleado por Brenda Laurel en Computers as Theatre: «The recapitulation of previous forms seems to be as intrinsic to the evolution of media as it is to the development of human individuals in the womb: Human embryos have gills and tails before they assume uniquely human shape; television emulated theatre, vaudeville, radio, and film. The emergence of a new medium is a dance between the evolutionary pattern or recapitulation and the force of creative visions» (1993: 193).

${ }^{6} \mathrm{Su}$ definición de medio se vuelve casi tautológica: «A medium is that which remediates. It is that which appropriates the techniques, forms, and social significance of other media and attempts to rival or refashion them in the name of the real» (1999: 65). 
ciden en querer crear la impresión de autenticidad, aunque en el segundo caso la experiencia de lo real pasa por la aceptación y toma de consciencia de la lógica y las convenciones del medio ${ }^{7}$.

¿Valen los conceptos de Bolter y Grusin para ser aplicados al teatro? Chapple y Kattenbelt (2006) responden afirmativamente, no sin antes incorporar de nuevo a la discusión el trabajo de Philip Auslander (1999). Hemos visto cómo el teatro actual problematiza las ideas de presencia (liveness) y mediatización a través de la incorporación de las nuevas tecnologías: «Theatre is an hypermedium that incorporates all arts and media and is the stage of intermediality» (Chapple y Kattenbelt, 2006: 20). La definición misma de teatro sería modificada con la irrupción de nuevas prácticas escénicas, que no respetarían la condición de co-presencia simultánea de actores y público, que prefieren emplear acciones grabadas (esto es, mediatizadas, sin vida) o poner en escena las posibilidades que ofrece la telepresencia.

En todo este proceso, el escenario se ha vuelto profundamente rizomático, pues en el rizoma de Deleuze y Guattari está la idea de interconexión de signos en un mapa de experimentación constante, de proliferación de conexiones entre elementos o nudos heterogéneos, de multiplicidad dinámica, sin centro, dentro de una red absolutamente abierta: «Un rizoma no cesaría de conectar eslabones semióticos, organizaciones de poder, circunstancias relacionadas con las artes, las ciencias, las luchas sociales. Un eslabón semiótico es como un tubérculo que aglutina actos muy diversos, lingüísticos, pero también perceptivos, mímicos, gestuales, cogitativos» (2003: 17). Se trata de abrirse a la «conexión de los campos, al desbloqueo de los cuerpos sin órganos, a su máxima apertura en un plan de consistencia», porque el mapa es «conectable en todas sus dimensiones, desmontable, alterable, suceptible de recibir constantemente modificaciones» (2003: 27-28). En el rizoma está, por último, la posibilidad de una dinámica «autopoiética y autoorganizadora» de actualización constante de la información ${ }^{8}$.

\footnotetext{
${ }^{7}$ Resulta imprescindible para estas cuestiones la consulta del libro de Lev Manovich (2001), en donde el punto de comparación para el desarrollo de las nuevas tecnologías es la historia del cine. Ahí se encontrará una detallada descripción del nuevo cine digitalizado y de sus estrategias de inmediación (véanse, por ejemplo, las páginas 147-ss., 287-ss y 309-ss).

8 «A diferencia de los árboles o de sus raíces, el rizoma conecta cualquier punto con otro punto cualquiera, cada uno de sus rasgos no remite necesariamente a rasgos de la misma naturaleza; el rizoma pone en juego regímenes de signos muy distintos e incluso estados de no-signos. El rizoma no se deja reducir ni a lo Uno ni a lo Múltiple. No es lo Uno que deviene dos, ni tampoco que devendría directamente tres, cuatro o cinco, etc. No es un múltiple que deriva de lo Uno, o al que lo Uno se añadiría (n+1). No está hecho de unidades, sino de dimensiones, o más bien de direcciones cambiantes. No tiene ni principio ni fin, siempre tiene un medio por el que crece y desborda. Constituye multiplicidades lineales de $n$ dimensiones,
} 


\section{INTERACTIVIDAD (¿DÓNDE ESTÁ EL AUTOR?)}

«Go in instead of look at». Este célebre lema de Allan Kaprow nos introducía en la necesidad de hacer participar al espectador en un espacio espectacular sensible e interactivo, y la performance se alejaba así de una concepción tradicional de la teatralidad, como ha señalado Margaret Morse:

It is as if the audience in this new kind of theater were free to cross the proscenium and wander about on stage, contemplating the actors' makeup and props, able to change point of view, to hear actors' asides, seeing both the process of creating an imaginary world and - more dimly than before- the represented world itself. But the difference can be even more radical, for in performance art, as opposed to traditional theater, the body of the performer and his or her experience in a here-and-now can be presented directly and discursively to an audience, which thereby becomes a you, a partner inhabiting the same world, possessing the capacity to influence as well as respond to events (1998: 161).

En cierto modo, la idea de entorno (environment), como supo ver Michael Fried (1967), una manifestación más de la crisis teatralizadora del objeto estético, se convertía en eje de muchas prácticas artísticas del siglo Xx, y en un entorno el artista busca la implicación del público, su participación activa y experiencial. Así lo hicieron Tadeusz Kantor en los primeros espectáculos del teatro CRICOT 2 o Augusto Boal, a quien se debe la creación del neologismo espectactor, descartado de inmediato como una mala palabra.

No todo el arte digital es interactivo, pero es indudable que sólo en la interactividad más abierta encuentra el arte digital una configuración completa. En una pieza teatral interactiva, la posibilidad de modificar la forma en el momento en que se crea se pone a disposición de todos los participantes, ya sea el artista, ya sean los espectadores. Se trata de apropiarse y personalizar el mensaje recibido, implicando al participante en la constitución del proceso comunicativo artístico. En el caso del teatro interactivo, es la interacción

\footnotetext{
sin sujeto ni objeto, distribuibles en un plan de consistencia del que siempre se sustrae lo Uno (n-1). Una multiplicidad de este tipo no varía sus dimensiones sin cambiar su propia naturaleza y metamorfosearse. Contrariamente a una estructura, que se define por un conjunto de puntos y de posiciones, de relaciones binarias entre estos puntos y de relaciones biunívocas entre esas posiciones, el rizoma sólo está hecho de líneas: líneas de segmentaridad, de estratificación, como dimensiones, pero también línea de fuga o de desterritorialización como dimensión máxima según la cual, siguiéndola, la multiplicidad se metamorfosea al cambiar de naturaleza [...] El rizoma es una antigenealogía, una memoria corta o antimemoria. El rizoma procede por variación, expansión, conquista, captura, inyección» (47-48). Cf. Lévy (1997: 121).
} 
misma la que da nacimiento a la obra. La interacción se produce a través de la mediación de una máquina o de un sistema informático, que el artista o el espectador (inter-actores, los llama Johannes Birringer) han de manipular de alguna manera: las interfaces que «permiten la interacción entre el universo de la información digitalizada y el mundo ordinario» (Lévy, 1997: 22): pueden ser dispositivos informáticos como un teclado, los ratones, las superficies sensibles a la presión de un dedo (las pantallas táctiles), los tectores ópticos o de sonido, los captadores automáticos de movimiento o los sensores que envían información al ordenador sobre ondas cerebrales, influjos nerviosos o condiciones físicas (calor, luz, humedad) para que sea procesada. El resultado se asemeja, en los ejemplos más extremos, a lo que se ha dado en llamar escena inteligente, abierta, imprevisible e inestable, multilineal, que depende de la implicación física del utilizador, aunque lo más habitual es que el tipo de interacción permanezca en la esfera de lo externo y exploratorio, y que debe dejar un margen amplio a la capacidad improvisatoria de los ejecutantes ${ }^{9}$. El diálogo entre el intérprete y el sistema informático pone en cuarentena la idea misma de autoría/autoridad, pues la pieza teatral depende de los significados programados por el ordenador, sometidos a su vez a la intervención humana. La interactividad cancela en cierto modo el cierre de la obra y la introduce en el ámbito de la impredecibilidad. Por otra parte, la noción de escritura teatral se pasa así por el filtro muy selectivo del conocimiento y la competencia tecnológica y obliga, en la mayor parte de las ocasiones, a un trabajo en equipo que diluye la responsabilidad individual de un único creador. En definitiva, la interactividad conduce a la consideración de la pieza como meta-performance, pues en cada proyecto va ímplicito el cuestionamiento de la realidad escénica como intensamente artificializada, como construcción o como construirse en el mismo acto de creación.

\subsection{Artista-máquina}

Emanuele Quinz (2006) ofrece algunos ejemplos ulteriores relacionados con la interacción del artista con las nuevas tecnologías. Bastarán ahora

\footnotetext{
9 Sigo aquí la tipología de Marie-Laure Ryan (2006: 107-125), que diferencia modos de interactividad a partir de las oposiciones externo/interno y exploratorio/ontológico. El modo interno supone que los usuarios se proyectan como miembros activos de un mundo virtual. El modo ontológico implica que cada decisión del usuario conlleva la aparición de un mundo posible distinto, a la manera borgiana de los senderos que se bifurcan. Para los efectos improvisatorios de la interacción cf. Coniglio (2004: 9).
} 
dos. En In Plane (1992), la Troika Ranch Company parte de los experimentos de John Cage o Merce Cunningham para crear un solo coreográfico en el que Dawn Stoppiello se conecta a un sistema informático de motion capture (MiniDancer) que amplifica el sonido en función de sus movimientos y que desdobla su imagen proyectada para el espectador (Coniglio, 2004). En Movatar (2000), Stelarc utiliza un dispositivo en parte opuesto al anterior, pues el movimiento corporal del performer está aquí provocado por una especie de avatar informático, una inteligencia externa informatizada. Son dos ejemplos del paradigma conexionista (Morignat, 2004) ${ }^{10}$.

Orgia (2002), pieza de Pasolini dirigida por Jean Lambert-Wild en el Théâtre National de la Colline (París), juega con el valor rítmico de la poesía escénica haciéndolo interactuar con actores virtuales presentes en escena en forma de holograma, creados gracias al sistema Daedalus. Los actores están equipados con captores que transmiten sus niveles de estrés y emoción a un ordenador, que a su vez los reenvía hacia estas criaturas artificiales, entes autónomos que simbolizan los fantasmas a los que la extraña pareja protagonista ha de hacer frente.

\subsection{Espectador-máquina}

Christa Sommerer y Laurent Mignonneau crearon en 1996 (Madrid, Arco; cf. Grau, 2003) un entorno interactivo en tiempo real titulado A-volución. El resumen recogido en Internet es suficientemente explícito:

Los visitantes interactúan con criaturas virtuales en el espacio de un estanque de cristal lleno de agua. Estas criaturas virtuales son producto de normas evolutivas y sufren la influencia de la creación y decisión humanas. Diseñando cualquier forma o perfil con el dedo en una pantalla sensible al tacto, los visitantes «soportan» criaturas virtuales en tres dimensiones, automáticamente «vivas» y nadando en el agua real del estanque. El movimiento y comportamiento de la criatura virtual lo decide su forma, el modo en que el observador la diseña en la pantalla ${ }^{11}$.

La interacción se produce aquí en múltiples niveles: los espectadores pueden crear criaturas tridimensionales dibujando en una pantalla sensible

${ }^{10}$ Es fundamental, para una aplicación de la noción de avatar al teatro contemporáneo, ver el último capítulo del libro de Susan-Ellen Case (2007: 163-207). Para una visión más generalista, Ryan (2006).

11 En http://www.fundacion.telefonica.com/at/avolve.html. 
formas bidimensionales; esas criaturas interactúan además con el observador, ya que éste puede detenerlas, favorecer su apareamiento, protegerlas...

\subsection{Espectador-máquina-artista}

Si en Afasia (1998) el performer Marcel.lí Antúnez ejercía de único manipulador de los materiales cibernéticos, en Epizoo (1994) eran los espectadores los que manipulaban, gracias a una pantalla de ordenador sensible, su cuerpo robotizado, cubierto por un exoskeleton que llevaba el cuerpo humano al límite del dolor.

Para Guillermo Gómez-Peña, que se ha mostrado siempre crítico con el empleo «utopista» de las nuevas tecnologías, la ilusión de interactividad ha cambiado la relación entre live art y su público, que, sobre todo si es joven, se resiste cada vez en mayor medida a permanecer pasivo contemplando una performance ${ }^{12}$. Esto supone un importante reto para los artistas, que deben incluir a toda costa la interacción entre los procedimientos operativos de su espectáculo. Desde la perspectiva de la participación activa del espectador, Guillermo Gómez-Peña ha puesto en funcionamiento performance-installations como Temple of Confessions (1994), en la que el público era invitado a hacer explícitos sus temores y angustias interculturales acogiéndose a uno de estos tres medios: la grabación de sus voces con unos micrófonos en el transcurso de la instalación (luego esas voces eran convenientemente alteradas electrónicamente para proteger su anonimato); la escritura de unas postales que se depositaban en una urna; o un número ochocientos a disposición del público las veinticuatro horas del día. Las confesiones elegidas por Gómez-Peña y Sifuentes eran recitadas en el transcurso del espectáculo, tal y como ellos mismos han explicado (GómezPeña, 2000: 35-ss.).

12 «They’ve been trained by TV, SuperNintendo, video games, and the Internet to «interact» and be part of it all. They see themselves as «insiders» and part-time artists. They've got the most recent software to make digital movies and compose electronic music. They burn their own CDs and design their own websites. To them there is nothing esoteric about art. Therefore, when attending a live art event, they wish to be included in the process, talk back to the artist, and, if possible, become part of the actual performance. These new audience members are always ready to walk on stage at any invitation from the artist and do someth006Cing, particularly if participation involves impersonating other cultures or taking off their clothes. It's karaoke time. It's like a live computer game with the added excitement that people, 'real people', are watching» (Gómez-Peña, 2005: 54). 


\section{TEATRO VIRTUAL}

En Virtual Theatres, Gabriella Giannachi, que se sitúa en la estela del pensamiento de Pierre Lévy (1997), define el teatro virtual como una variedad de formas que comparten «the characteristic of being open works in which the viewer is variously participating to the work of art from within it» (2005: $4)$. De este modo, el libro no se ocupa del teatro sino de la teatralidad inherente de las nuevas tecnologías. El teatro virtual es a la vez remediado, inmersivo e interactivo: su contenido es el propio medio a la vez que su relación con otros (medios), y su carácter es metadiscursivo, intertextual e intermedial; el performer se encuentra dentro de la obra de arte, no metafórica sino ontológicamente (2005: 7), a través de una realidad virtual que sólo aparece cuando él está dentro de una simulación; la participación puede suponer además la telepresencia, la conjunción gracias a las nuevas tecnologías de dos o más espacios diferentes alejados entre sí.

La interesante caracterización de Giannachi es, por supuesto, demasiado extendida, y por ello no es extraño que los productos analizados vayan desde los hipertextos, los videojuegos o los MUDs o MOOs hasta los ejercicios pioneros de realidad virtual, al estilo de The Adding Machine (1994), un texto de Elmer Rice sobre la lucha entre el hombre y las máquinas, o Wings (1996), dos espectáculos con escenografía de Mark Reaney, profesor de teatro y cine en la Universidad de Kansas, que utilizaban la tecnología de la realidad virtual para ampliar considerablemente las posibilidades espaciales de la ficción teatral. Los espectadores, provistos de cascos «catódicos», visualizaban imágenes que encuadraban la interpretación de los actores, de manera que la representación alternaba con la simulación: en «Catastrophe», la primera secuencia de Wings, se presenciaba una sucesión alucinatoria de cielos que se mueven, relojes que vuelan o vehículos que se desplazan por todas partes... Luego se asiste a una consulta médica en la que el propio espectador es el paciente (sigo la descripción de Franck Bauchard, 1998) $)^{13}$.

13 Pueden leerse en red los artículos del propio Reaney «Théâtre et réalité virtuelle: un art en temps reel» (2000) y «Virtual Scenography: The Actor/Audience/Computer Interface» (1996), en donde se define la RV como «a computer simulation of real imaginary environments and [that] these simulations are 'interactive', capable of being navigated or manipulated in real-time rather than being pre-recorded». Es interesante cotejar las experiencias de Reaney con las de Brenda Laurel en Placeholder (1992), una instalación en la que el público era realmente el protagonista y en la que no existía, en rigor, un principio o un final. 


\section{5. «REALIDAD AUMENTADA»}

Es ésta una expresión que se encuentra en muchos de los trabajos dedicados a la relación entre el teatro y las nuevas tecnologías, que permitirían a la puesta en escena amplificarse y multiplicarse en una forma de hiper-realidad, de modo que nos hallaríamos ante lo que Paul Virilio llamaría realidad estéreo, conjunción o superposición acelerada de la «realidad actual de las apariencias inmediatas» y de la «realidad virtual de las transparencias mediáticas» (1999: 25 y 133), una manifestación más del deseo obsesivo por estar conectado o en red.

En escena, las pantallas se multiplican. El vídeo se convirtió desde muy pronto en un fiel compañero del teatro, y la conjunción de los dos medios alcanzó un éxito notable en espectáculos como Route $1 \& 9$ (The Last Act) (1981) de The Wooster Group, donde, a medida que nos acercamos al final, el papel de los actores en vivo va perdiendo fuerza delante de la actuación emitida por los monitores de televisión y creando lo que Nick Kaye ha llamado performance across media (2007: 164-181). La incorporación de la informática también conduce hacia a una performance mediatizada donde la distinción entre medios (por ejemplo, entre teatro y cine) se atenúa o desaparece (Auslander, 1999), como en muchos de los trabajos de Laurie Anderson, especialmente en United States (1983) o en la grandiosa Moby Dick (1999). Dentro de los proyectos del Massachusetts Institute of Technology, Claudio Pinhanez presentó en 1997 su pieza $I t / I$, que indagaba en las posibilidades de los ordenadores para crear un entorno de interacción entre hombre y máquina. La extensión del cuerpo del actor por medios informáticos lo convertía en un hiper-actor (Jensen, 2007: 13).

En 1998, Robert Wilson estrenaba Monsters of Grace 1.0 (su título procede de un error en el recitado de un verso de Hamlet, «Angels and Ministers of Grace», cometido por el director un año antes durante su célebre «oneman-show»), ópera digital con música de Philip Glass y libreto del poeta místico sufí del siglo XIII Jalaluddin Rumi, donde el público, habilitado con unas gafas 3D, asistía a la escenificación de algunos poemas persas protagonizada por 'actores de síntesis', «numéricos», en proyección estereoscópica. El espectáculo, de un coste enorme, constaba de trece cuadros, ocho de los cuales creados a través de un filme en tres dimensiones de sesenta y ocho minutos de duración. El resultado no fue del todo satisfactorio ni para la crítica ni para el propio Wilson, que perdió en seguida el control sobre la parte animada, realizada durante un año por veinte especialistas de Kleiser-Walczak 
Construction Company ${ }^{14}$. Esta virtualidad acrecentada pretendería reubicar el teatro en el debate sobre el regreso a la imagen (sobre su voracidad), que caracteriza el último pensamiento del siglo XX.

Los ejemplos de esta realidad aumentada podrían multiplicarse. Ahí están los espectáculos, comentados por Dixon, de David Saltz (Tempest 2000), Christian Ziegler (Scanned, 2000), Bud Blumenthal (Les Entrailles de Narcisse, 2001), Troika Ranch (The Chemical Wedding of Christian Rosenkreutz (2001) o Anja Diefenbach y Christoph Rodatz (Cyberstaging Parsifal, 2002), donde el cuerpo físico de los actores se combina con la proyección de diapositivas y vídeo sobre grandes pantallas divididas y con los efectos digitales de última generación que crean cuerpos virtuales o avatares para el espectador. De hecho, algunas compañías, como Dumb Type, Blast Theory, The Builders Association o George Coates Performance Works, se han venido especializando en el empleo de las nuevas tecnologías para crear escenografías artificiales y entornos espaciales que pretenden provocar un efecto inmersivo gracias a la hibridación de lo real y lo virtual.

\section{LA NUEVA CORPORALIDAD DE LO POST-HUMANO}

Para los artistas de las performances digitales, el cuerpo humano se convierte en un campo de experimentación primordial, dado su carácter flexible e inestable, material y sexualizado a la vez que territorio donde operan la simulación y las convenciones sociales. El libro de Tracey Warr (2006) es generoso en ejemplos de cómo en el siglo Xx el cuerpo se ha sometido a toda suerte de transformaciones liberadoras, de cómo se lo ha querido llevar al límite, de cómo la idea de un yo hermenéutico y esencialista (el llamado sujeto cartesiano) se ha visto superado gracias a las aportaciones tecnológicas. Ahí están la estética cyborg y las representaciones tecnofílicas o tecnofóbicas del ser humano: pensemos en los cuerpos prolongados y protésicos en los que los artistas buscan la metamorfosis de su cuerpo mediante prótesis o tecnología, explorando estados de conciencia alternativos. Como señala

14 Así describía el espectáculo de Wilson el crítico de The New York Times Bernard Holland: «The episodes of 'Monsters of Grace' are disconnected and tell no story. Disembodied tubes or vessels lead to a giant amputated hand rendered so close that it might chuck us under the chin. Helicopters roam a gauzy Himalayan landscape. A table set with chopsticks hovers near. A polar bear lounges, a shoe drops, a snake slithers. Mr. Wilson's trademark crossing bars of light present themselves. (They hint at the intersection of time and space, he said at a pre-event panel discussion.)». Cf. Dixon (2006: 25-29) y Shevtsova (2007: 36-37). 
Tim Etchells, «the theatre must take account of how technology [...] has rewritten and is rewriting bodies, changing our understanding of narratives and places, changing our relationships to culture, changing our understanding of presence» (1999: 97; cf. Gray, 1995). En este sentido, es obvio que la tecnología digital desmaterializa y virtualiza el cuerpo humano, pues la imagen proyectada carece de aura y está liberada de su realidad (Cornago, 2004).

Stelarc ha proclamado que el cuerpo se ha vuelto obsoleto y Orlan se ha dedicado con testarudez a mejorarlo. En The Third Hand (1976-1980), Stelarc superponía sobre la mano derecha una tercera del mismo tamaño, que estaba conectada a través de dispositivos eléctricos a los músculos del abdomen y la pierna. Con esa tercera mano el performer podía manipular objetos y escribir. Omniprésence (1993) supuso la séptima performance-intervención de Orlan, retransmitida vía satélite desde la Sandra Gering Gallery de Nueva York a quince espacios de todo el mundo (entre ellos el Centro Georges Pompidou de París, el McLuhan Center de Toronto y el Multi-Media Center de Banff). En la descripción de Tracey Warr (2006: 185) se explica que los espectadores pudieron hablar con la artista antes y durante la operación, que Orlan transformó el quirófano en un espacio teatral de colores vivos en donde la cirujana feminista Marjorie Cramer realizó implantes en los ojos, las mejillas y la barbilla de la artista, que permaneció siempre consciente. Después vendría la exposición de las fotografías de su rostro magullado en comparación computerizada con el de algunas diosas de la mitología griega, con el fin de subrayar «la deformidad y el dolor físicos que tenía que soportar para lograr una belleza culturalmente idealizada» (ibid.). Los de Stelarc u Orlan son cuerpos tecnológicos, fragmentados y abiertos al reconocimiento de la tecnologización del yo, y nos hacen reflexionar sobre la importancia del cuerpo medicalizado, en cualquiera de sus variantes, en el interior de una sociedad actual que ha canonizado los estándares de belleza: «Her forehead is from Leonardo's Mona Lisa; her chin from Botticelli's Venus; her nose from an attributed sculpture of Diana by l'École de Fontainebleau; her mouth from Gustave Moreau's Europa; and her eyes from François Pascal Simon Gérard's Psyche [...] Everything about Orlan is artifice, from her name to her body, which remains a work in progress [...], No longer art imitates life. In Orlan, life imitates art» (Giannachi, 2005: 49-50). Orlan pone en juego los tres cuerpos distinguidos por Don Ihde (2002): el cuerpo uno es el físico, el que nos permite estar-en-el-mundo; el dos es una construcción social y cultural; el tres supera los dos anteriores con el añadido de lo tecnológico, de la telepresencia o de lo virtual. 
Matthew Causey (2006: 52-58) ha estudiado la presencia de lo post-orgánico y la extensión de la subjetividad en proyectos de Eduardo Kac, el creador del arte transgénico, o Romeo Castellucci (Societas Raffaello Sanzio). Lo post-orgánico es aquí un término no exento de connotaciones profundamente éticas, que Causey no descuida en su análisis, un término que apunta de nuevo a la pérdida de presencia y aura y a la exploración tecnológica en los nuevos modos de manipular el espacio, el tiempo y la subjetividad: el humano y la máquina, finalmente, no se diferencian entre sí. Lo virtual se define en este contexto como un tipo de comunicación descorporeizada o desnaturalizada por la necesidad de imponer la ausencia de lo humano, sustituido por su proyección en una pantalla, también como una nueva manera de percibir la subjetividad contemporánea en un mundo implementado sin remedio por las nuevas tecnologías.

\section{CRÍTICA DE LA RAZÓN TECNOLÓGICA: SI TODO ES TEATRO, NADA ES TEATRO}

En las monografías de Giannachi o Dixon encontramos una idea de teatralidad expandida que utiliza los conceptos de manera analógica o metafórica. Seguramente es así desde que Brenda Laurel publicó su Computers as Theatre (1991), en donde la teoría dramática de Aristóteles se convertía en el sustento del análisis de las nuevas textualidades electrónicas a partir de la Poética de Aristóteles. La situación se vio en parte agravada por la excepcional aportación de Janet H. Murray (1999), en donde el llamado ciberteatro/ciberdrama se definía por sus cualidades de inmersión (penetrar en un entorno artificial completamente ajeno al nuestro o real), actuación (participación activa en el interior de ese entorno) y transformación (constante cambio de apariencia o forma del mismo mensaje). Los nuevos medios cuentan las mismas historias adaptadas a estas posibilidades emergentes, que más recientemente han sido analizadas en el libro coordinado por Noah WardripFruin y Pat Harrigan (2004).

No hay duda de que un examen serio de estas aproximaciones nos las revela como excesivas y poco rigurosas, pero, al mismo tiempo, corremos el riesgo de caer en un esencialismo reductor. Nadie sabría responder hoy en día a la cuestión de qué es el teatro, mucho menos en el contexto del teatro posdramático. Pero si partimos de una definición canónica, la que defiende que el teatro es un asunto de seres humanos, los actores y los espectadores, en un espacio y tiempo compartidos, en seguida encontraremos elementos 
para la discusión: ¿puede haber un teatro sin espectadores?, ¿puede haber un teatro sin actores?, ¿puede haber un teatro sin un espacio físico compartido?, ¿puede por último haber un teatro sin un tiempo real compartido?

Sin ánimo ni capacidad de dar respuestas definitivas, deben problematizarse las preguntas arriba planteadas. Podemos entender la existencia de un teatro participativo, en el que el espectador se sume activamente al universo escénico, o de una escena creada gracias a la proyección delante de un público de imágenes telemáticas o grabadas en tiempo real, con la que interactúan los actores. Pero, ¿aceptaríamos como teatro la grabación de la performance de unos actores y su proyección ulterior delante de un público? Sin duda, no. Todos sabemos que eso se llama cine, aunque en los orígenes se lo considerase teatro remediado.

Estamos, como decía Janet Murray, en una época de incunabilidad electrónica, en la que echamos mano de lo conocido para nombrar lo nuevo: las nuevas tecnologías, como antes el cine de los orígenes o la televisión, se anclan en la idea de teatro. En este sentido, ¿es teatro un videojuego? Mi respuesta es aquí rotundamente negativa, por muy lejos que se lleve la aplicación de la idea de performance. El teatro no es sólo lo teatral. Hay teatralidad en el cine, en los vídeojuegos o en los juegos de roles, como la puede haber en una novela. Pero no es de recibo hablar para estos casos, si no es metafóricamente, de teatro.

Cuando hablamos de la creación de una Realidad Virtual a la que nos incorporamos como agentes (V-actores, según Carver y Beardon, 2004: 168169), no se puede, no habiendo propiamente actores (o espectadores, según se mire), hablar de teatro. Cuando presenciamos una performance on line o en CD-ROM, tampoco. ¿Alguien diría que es teatro la retransmisión televisiva en directo de un espectáculo teatral o su grabación en DVD? En ambos casos, la mediación de una máquina tiene fuertes implicaciones en lo que se refiere a la creación de significados por parte del espectador. Se trata de la atracción por una mirada artificial a través de máquinas de visión, como señalaría Paul Virilio (1998). Las implicaciones de esta mediatización, acentuada en el caso de las telepresencias, son muy profundas en el ámbito del actor, del espacio escénico y del espectador, de manera que se ajustan muy bien las palabras de este crítico del cibermundo: «Disuadir, así, al teatro de ser teatro, dicho de otro modo, la manifestación de un cuerpo (en la escena) en la era de la ficción de los clones, de los avatares (en la pantalla) de la realidad virtual, ¡he aquí la nueva paradoja del comediante!» (1999: 139). El actor se confunde con el espectador, y la misma corporalidad se pone en tela de juicio. 
Al comentar el espectáculo de Robert Lepage, Zulu Time (1999), Patrice Pavis reconocía que la tecnología se ha vuelto omnipresente, aunque en su opinión su uso no está exento de paradojas: cuanta más tecnología, más necesidad para el espectador de cuerpos humanos auténticos, portadores de palabras. La tecnología no puede volverse un fin en sí mismo, a riesgo de volverse ridícula y autoritaria. Entiéndase lo dicho por Pavis como una palinodia humanística por un teatro puro que nunca ha de volver. En efecto, si la aparición de las nuevas tecnologías está ayudando a desarrollar un nuevo teatro de lo intermedial, conviene advertir que en este tipo de experiencias «true greatness is rare» (Dixon, 2006: 6). Más allá de romantizar la condición tecnológica, el funcionamiento de lo nuevo o lo electrónicamente sofisticado ni implica ni mucho menos garantiza para el espectador una experiencia estética satisfactoria. Por supuesto, no vale abusar tampoco del criterio de la interactividad. La interactividad es un valor añadido al teatro, nunca, como a veces, en un razonamiento silogístico, se quiere ver, un rasgo definitorio. Gracias a las nuevas tecnologías se crea un nuevo teatro interactivo, pero el teatro interactivo no es teatro en un grado más intenso que cualquier otro. Ni siquiera es teatro mejor. En nuestros días, todos soportamos experimentos teatrales que incorporan lo digital de manera improductiva. La ecuación Teatro+Digital=Digital nos pone en la pista de que el medio todavía llama demasiado la atención sobre sí mismo, convirtiéndose en un obstáculo, pues rompe con la aspiración de lo digital de ser inmediato («la inmediata absorción de la imagen por los sentidos»), por volver a la terminología de Bolter, o de provocar inmersión, si nos referimos ahora a la de Murray (cf. Baugh, 2005). Ése es el riesgo, permanecer en la esfera de la artificialidad absoluta del espectáculo, como ha visto Andrew Darley: «Vacío de contenido, despojado del peso de la progresión ficcional, la astucia del espectáculo consiste en que empieza y acaba con su propio artificio; en cuanto tal, el espectáculo exhibe y, simultáneamente, se exhibe» (2002: 167).

Los excesos de la tecnología llevaron a algunos creadores teatrales a poner en marcha una via regresiva o negativa que consistía en la defensa de la pureza del teatro. Al lado de las propuestas de Jerzy Grotowsky o Peter Brooks, debe tenerse en consideración la existencia de un teatro que quiere alcanzar la idea de totalidad gracias a la incorporación de las nuevas tecnologías. Está por ver su alcance real, pero nadie puede dudar hoy de que se trata de un camino sin retorno, con sus hitos ya establecidos: el teatro ha incorporado y aceptado la experiencia tecnológica como propia, igual que ahora las nuevas tecnologías aplicadas al arte buscan en la teatralidad una tarjeta de presentación legitimadora. Pero, no lo olvidemos, las sendas de la re- 
mediación son intrincadas y luego habrán de venir los tiempos (quizás ya están aquí) en que la identidad ciberartística se defina precisamente por sus propios logros, esto es, en oposición a un teatro que, mirando hacia atrás o hacia delante, seguirá siendo una metáfora fundamental de la existencia humana y post-humana.

\section{REFERENCIAS BIBLIOGRÁFICAS}

ABuín, A. (2006). Escenarios del caos. Entre la hipertextualidad y la performance en la era electrónica. Valencia: Tirant lo Blanch.

Auslander, Ph. (1999). Liveness. Performance in a Mediatized Culture. Londres: Routledge.

Balme, Ch. (1999). Einführung in die Theaterwissenschaft. Berlín: Eric Schmidt.

BARDIOT, C. (2003). «L'Acteur interfacé. De l'omniprésence à la transparence de la technologie sur le plateau numérique». L'acteur entre personnage et performance. Présences de l'acteur dans la représentation contemporaine. Études théâtrales 26, 87-91.

BAUCHARD, F. (1998). «Théâtre et réalité virtuelle. Une introduction à la démarche de Mark Reaney». En Les Écrans sur la scène, B. Picon-Vallin (ed.), 225-245. Lausanne: L'Age d'Or.

- (2003). «Esthétiques des mutations scéniques». Arts de la scéne, scène des arts II. Limites, horizon, découvertes: mille plateaux. Études théâtrales 28-29, 131-138.

Baugh, Ch. (2005). Theatre, Performance and Technology. The Development of Scenography in the Twentieth Century. Nueva York: Palgrave MacMillan.

BIRRINGER, J. (2006). «Interacting». Contemporary Theatre Review 16.4, $389-405$.

Bolter, J. D. (2001). Writing Space. Computers, Hypertext, and the Remediation of Print. New Jersey: Lawrence Erlbaum Associates.

Bolter, J. D., y Richard GRUSIN (1999). Remediation. Understanding New Media. Cambridge, Mass.: The MIT Press. 
BREA, J. L. (2002). La era postmedial. Acción comunicativa, prácticas (post)artísticas y dispositivos neomediales. Salamanca: Centro de Arte.

- (2005). «Nuevos dispositivos del arte. Transformaciones de las prácticas artísticas en la era del capitalismo cultural electrónico». Telos 56, 55-73.

Callens, J. (2003). «Les expériences tecnologiques du Wooster Group». L'acteur entre personnage et performance. Présences de l'acteur dans la représentation contemporaine. Études théâtrales 26, 80-83.

Carver, G. y C. BeArdon (eds.) (2004). New Visions in Performance. The Impact of New Technologies. Lisse: Swets \& Zeitlinger.

CASE, S.-E. (2007). Performing Science and the Virtual. Londres: Routledge.

Causey, M. (2006). Theatre and Performance in Digital Culture. From Simulation to Enbeddedness. Londres: Routledge.

Chaple, F. y Ch. Kattenbelt (2006). Intermediality in Theatre and Performance. Amsterdam: Rodopi.

Coniglio, M. (2004). «The Importance of Being Interactive». En New Visions in Performance. The Impact of New Technologies, G. Carver y C. Beardon (eds.), 5-12. Lisse: Swets \& Zeitlinger.

Copeland, R. (1990). «The Presence of Mediation». The Drama Review 34, $4,28-44$.

- (1999). «Cunningham, Collage, and the Computer». PAJ: A Journal of Performance and Art 21.3, 42-54.

Cornago, Ó. (2004). «El cuerpo invisible. Teatro y tecnologías de la imagen». Árbor 699-700, 595-610.

CRitical ART Ensemble (2000). «Recombinant Theatre and Digital Resistance». The Drama Review 44, 4, 151-166.

DARLEY, A. (2002). Cultura visual digital. Espectáculo y nuevos géneros de comunicación. Barcelona: Paidós.

Deleuze, G. y Guattari, F. (2003). Rizoma. Valencia: Pre-Textos.

DiXON, S. (2007). Digital Performance. A History of New Media in Theater, Dance, Performance Art, and Installation. Cambridge, Mass.: The MIT Press.

Dubatti, J. (2003). El convivio teatral. Teoría y práctica de Teatro Comparado. Buenos Aires: Atuel. 
ETCHells, T. (1999). Certain Fragments: Contemporary Performance and Forced Entertainment. Londres: Routledge.

FOUQUET, L. (2005). Robert Lepage, l'horizon en images. Québec: L'Instant Même.

FrIED, M. (1967). «Art and Objecthood». En G. Battcock (ed.), Minimal Art: A Critical Anthology. Nueva York: Dutton.

Fuchs, E. (1985). «Presence and the Revenge of Writing: Re-Thinking Theatre after Derrida». Performing Arts Journal 9. 2-3, 163-173.

Galizia, L. R. (2004, ed. or. 1986). Os processos criativos de Robert Wilson. São Paulo: Perspectiva.

García Barrientos, J. L. (2004). Teatro y ficción. Ensayos de teoría. Madrid: Fundamentos.

GEMINI, L. (2003). L'incertezza creativa . I percorsi sociali e comunicativi delle performance artistiche. Milán: Francoangeli.

Giannachi, G. (2005). Virtual Theatres. An Introduction. Londres: Routledge.

- (2006). «Exposing Globalisation: Biopolitics in the Work of Critical Art Ensemble». Contemporary Theatre Review 16. 1, 41-50.

Gómez PeÑa, G. (2000). Dangerous Border Crossers. Londres: Routledge.

- (2005). Ethno-techno. Writings on Performance, Activism, and Pedagogy. Londres: Routledge.

Gordon, M. (1980). «Laurie Anderson: Performance Artist». Women and Performance. The Drama Review 24. 2, 51-54.

Grau, O. (2003). Virtual Art: From Illusion to Immersion. Cambridge, Mass.: The MIT Press.

GrAY, Ch. H. (ed.) (1995). The Cyborg Handbook. Londres: Routledge.

HARRIES, D. (2002). The New Media Book. Londres: BFI.

IHDE, D. (2002). Bodies in Technology. Electronic Meditations. Minneapolis: University of Minnesota Press.

Jensen, A. P. (2007). Theatre in a Media Culture. Production, Performance and Perception Since 1970. Jefferson: McFarland. 
JonEs, A. (1997). «'Presence' in Absentia: Experiencing Performance as Documentation». Art Journal 56. 4, 11-18.

KaYe, N. (2007). Multi-media. Video, Installation, Performance. Londres: Routledge.

Konigson, É. (ed.) (1995). L'Oeuvre d'art totale. París: CNRS.

LaURel, B. (1991). Computers as Theatre. Reading, Mass.: Addison-Wesley.

Lehmann, H.-Th. (1999). Le Théâtre postdramatique. París: L'Arche.

LÉvy, P. (1997). Cibercultura. La cultura de la sociedad digital. Barcelona: Anthropos.

Manovich, L. (2001). The Language of New Media. Cambridge, Mass.: The MIT Press.

MorignAT, V. (2004). «Environnements virtuels et nouvelles stratégies actantielles». Arts de la scène, scène des arts III. Formes hybrides: vers de nouvelles identités. Études théâtrales 30, 45-53.

Morse, M. (1998). Virtualities. Television, Media Art, and Cyberculture. Bloomington: Indiana U.P.

MüLLER, J. E. (1996). Intermedialität. Münster: Nodus Publikationen.

Murray, J. H. (1999, ed. or. 1997). Hamlet en la holocubierta. El futuro de la narrativa en el ciberespacio. Barcelona: Paidós.

PACKer, R., y Jordan, K. (eds.) (2001). Multimedia: From Wagner to Virtual Reality. Londres: Norton.

Paz GaGo, J. M. (2004). «Ciberteatro. Teatro y tecnologías digitales». En Teatro, prensa y nuevas tecnologías (1990-2003), J. Romera Castillo (ed.), 81-88. Madrid: Visor Libros.

PAVIS, P. (2003). «Afterword: Contemporary Dramatic Writings and the New Technologies». En Trans-global Readings: Crossing Theatrical Boundaries, C. Svich (ed.), 187-202. Manchester: Manchester U.P.

Petersen, K. Y. (2004). «The Emergence of Hyper-Reality in Performance». En New Visions in Performance. The Impact of New Technologies, G. Carver y C. Beardon (eds.), 31-40. Lisse: Swets \& Zeitlinger.

Phelan, P. (1993). Unmarked: The Politics of Performance. Londres: Routledge. 
PiCON-VAllin, B. (1998). «Hybridation spatiale, registres de présence». En Les Écrans sur la scène, B. Picon-Vallin, (ed.), 9-35. Lausanne: L'Age d'Or.

- (2003). «Les nouveaux défis de l'image et du son pour l'acteur. Vers un 'super-acteur'?». L'acteur entre personnage et performance. Présences de l'acteur dans la représentation contemporaine. Études théâtrales 26, 5968.

- (ed.) (2001). La Scène et les images. París: CNRS.

Pontbriand, Ch. (1982). «The Eye Finds No Fixed Point on Which to Rest». Modern Drama 25. 1, 154-162.

QuinZ, E. (2004). «Notes dur la scène des interfaces». Arts de la scène, scène des arts III. Formes hybrides: vers de nouvelles identités. Études théâtrales 30, 60-67.

Romera Castillo, J. (ed.) (2004). Teatro, prensa y nuevas tecnologías (1990-2003). Madrid: Visor Libros.

RYAN, M.-L. (2006). Avatars of Story. Minneapolis: University of Minnesota Press.

SANFILIPPO, M. (2004). «Teatro italiano e Internet». En Teatro, prensa y nuevas tecnologías (1990-2003), J. Romera Castillo (ed.), 455-464. Madrid: Visor Libros.

SHEvTsova, M. (2007). Robert Wilson. Londres: Routledge

Tofts, D.; Johnson, A. y Cavallero, A. (eds.) (2002). Prefiguring Cyberculture: An Intellectual History. Cambridge, Mass.: MIT Press.

Valiente, P. (2005). Robert Wilson. Arte Escénico Planetario. Madrid: Ñaque.

VIRILIO, P. (1998). La máquina de visión. Madrid: Cátedra.

- (1999). La bomba informática. Madrid: Cátedra.

WAGNER, P. (ed.) (1996). Icons - Texts - Iconotexts. Essays on Ekphrasis and Intermediality. Berlín y Nueva York: Walter de Gruyter.

WardriP-Fruin, N. y HARRIG, P. (2004). Firstperson. New Media as Story, Performance, and Game. Cambridge, Mass.: MIT Press.

WARR, T. (2006). El cuerpo del artista. Barcelona: Phaidon. 
Weber, S. (1996). Mass Mediauras. Form, Technics, Media. Stanford U. P. VV. AA. (1999). Theatre and Technology. Theatre Journal 51, 4.

VV. AA. (2003). Arts de la scène, scène des arts, I. Brouillages de frontières: une approche par la singularité. Études théatrales 27.

VV. AA. (2004). Theatrical Events. Borders, Dynamics, Frames. Amsterdam: Rodopi.

\section{Algunos recursos electrónicos de interés}

Anderson, Laurie: http://www.laurieanderson.com/

Antúnez, Marcel.lí: http://www.marceliantunez.com/

Barney, Matthew. Cremaster: http://cremaster.net/

Blast Theory: http://www.blasttheory.co.uk/

The Builders Association:

http://www.thebuildersassociation.org/flash/flash.html?homepage/

Barbosa, Pedro. Allestator XPTO-Kosmos 2001. http://alfarrabio.um.geira.pt/vercial/alletsator.htm/

Breeze, Marie Anne. Dielation manifesto: A sliver of the future. http://netwurkerz.de/mez/dielation.htm/

Company in Space: http://www.companyinspace.com/

Creating Digital Performance: http://ahds.ac.uk/creating/guides/performing-resources/contents.htm/

Critical Art Ensemble: http://www.critical-art.net/

Deemer, Charles. The Last Song of Violeta Parra: http://www.ibiblio.org/cdeemer/chile-m.html/

Digital Performance Archive: http://ahds.ac.uk/ahdscollections/docroot/dpa/authorssearch.jsp? string $=D /$

Dumb Type: http://dumbtype.com/

Electronic Arts Intermix: http://www.eai.org/eai/artists_titles.jsp/ 
Ex Machina: http://www.exmachina.qc.ca/intro.htm/

La Fura dels Baus: http://www.lafura.com/entrada/index2.htm/

Georges Coates Performance Works: http://www.georgecoates.org/

Gertrude Stein Repertory Theatre: http://www.gertstein.org/

Gómez-Peña, Guillermo: http://www.pochanostra.com/\#Scene_l/

Gonçalves Duarte, Eunice (2007). «Metamorfoses da mimesis: A dramaturgia na era tecnológica»:

http://www.educ.fc.ul.pt/hyper/resources/eduarte-mimesis.htm\#subl/

The Hamnet Players: http://www.marmot.org.uk/hamnet/

Hamlet X. En http://www.hamlet-x.del

i.e. VR (University of Kansas): http://www2.ku.edu/ ievr/

In Extremis Images: http://iei.anamorphoses.com/

Institute for the Exploration of Virtual Realities (Mark Reaney): http://www2.ku.edu/ ievr/

Interactive Story: http://www.interactivestory.net/

Intermediality and Performance: http://www.bodiescapes.de/site/intermediality.htm/

It/I. http://web.media.mit.edu/ iti/

Kac, Eduardo: http://www.ekac.org/

Kantor, Istvan: http://www.ccca.ca/performance_artists/k/kantor/kantor_perf18/index

Laterna Magika (Joseph Svoboda): http://www.laterna.cz/

Laurel, Brenda: http://www.tauzero.com/Brenda_Laurel//

Manovich, Leo, «The Poetics of Augmented Space»: http://www.manovich.net/DOCS/Augmented_2005.do

Me-Dea-Ex: http://medeaex.org/

Monk, Meredith: http://www.meredithmonk.org/

Morignat, Valérie \& Actazé: http://www.valeriemorignat.net/

Obermaier, Klaus: http://www.exile.at/ko/ 
Orgia: http://www.cdn-orleans.com/Orgia.htm/ http://www.colline.fr/ spectacle/index/id/41/rubrique/presentation/

Orlan: http://www.orlan.net/

Paik, Nam June: http://www.paikstudios.com/index.html/

Palindrome Intermedia Performance Group: http://www.palindrome.de/

The Plaintext Players: http://yin.arts.uci.edu/ players/

The Presence Project: http://presence.stanford.edu:3455/Collaboratory/9/

Robert Edmond Jones: http://www.robertedmondjones.com/

Rokeby, David: http://homepage.mac.com/davidrokeby/home.html/

Russell, Barry. Le Théâtre de la Foire: http://foires.net/

Sermon, Paul: http://www.hgb-leipzig.de/ sermon/

Smylie, Barry: http://barrysmylie.com/

Societas Raffaello Sanzio: http://www.raffaellosanzio.org/

Sommerer, Christa, y Laurent Mignonneau: http://www.interface.ufg.ac.at/christa-laurent/index.html/

Sparacino, Flavia: http://alumni.media.mit.edu/ flavia/

Stelarc: http://www.stelarc.va.com.au/

Studio Azzurro: http://www.studioazzurro.com/

Teatre virtual: http://www.teatrevirtual-mercatflors.net/

Tecnoescena: http://www.tecnoescena.com/

Templeton, Fiona: http://www.fionatempleton.org/

Troika Ranch Home: http://www.troikaranch.org/

Verde, Giacomo: http://www. verdegiac.org/

The Virtual Theater Project: http://www-ksl.stanford.edu/projects/cait/index.html/

Vuillemin, Alain, «Concepts informatiques et écritures théâtrales» : http://www.uottawa.ca/academic/arts/astrolabe/articles/art0029.htm\#A nalyse\%20descendantel

The Wooster Group: http://www.thewoostergroup.org/

Zapp, Andrea: http://www.azapp.del 